\title{
OPEN
}

\section{Characterizing absolute lymphocyte count profiles in dimethyl fumarate-treated patients with MS}

\section{Patient management considerations}

\author{
Robert J. Fox, MD; Andrew Chan, MD; Ralf Gold, MD; J. Theodore Phillips, MD, PhD; \\ Krzysztof Selmaj, MD, PhD; Ih Chang, PhD; Mark Novas, MD; Jitesh Rana, MD; Jing L. Marantz, MD, PhD
}

\begin{abstract}
Background: Delayed-release dimethyl fumarate (DMF), indicated for the treatment of patients with relapsingremitting multiple sclerosis (MS), is a disease-modifying therapy with potential immunomodulatory and neuroprotective effects. In clinical trials, DMF was associated with reduced white blood cell and absolute lymphocyte counts. Current US prescribing information recommends obtaining a complete blood count, including absolute lymphocyte count (ALC), before initiating and during DMF treatment. Methods: We conducted an integrated analysis of phase $2 \mathrm{~b} / 3 /$ long-term extension studies of DMF in MS $(N=2,470)$ to characterize ALC profiles. Results: Mean ALCs decreased by $30 \%$ during the first year and then plateaued, remaining above the lower limit of normal (LLN). Among patients treated $\geq 6$ months ( $N=2,099$ ), $2.2 \%$ experienced ALCs $<500$ $\mathrm{mm}^{3}$ persisting $\geq 6$ months. ALCs remained $\geq L L N$ in
\end{abstract} $84 \%$ and $76 \%$ of patients during the first 6 and

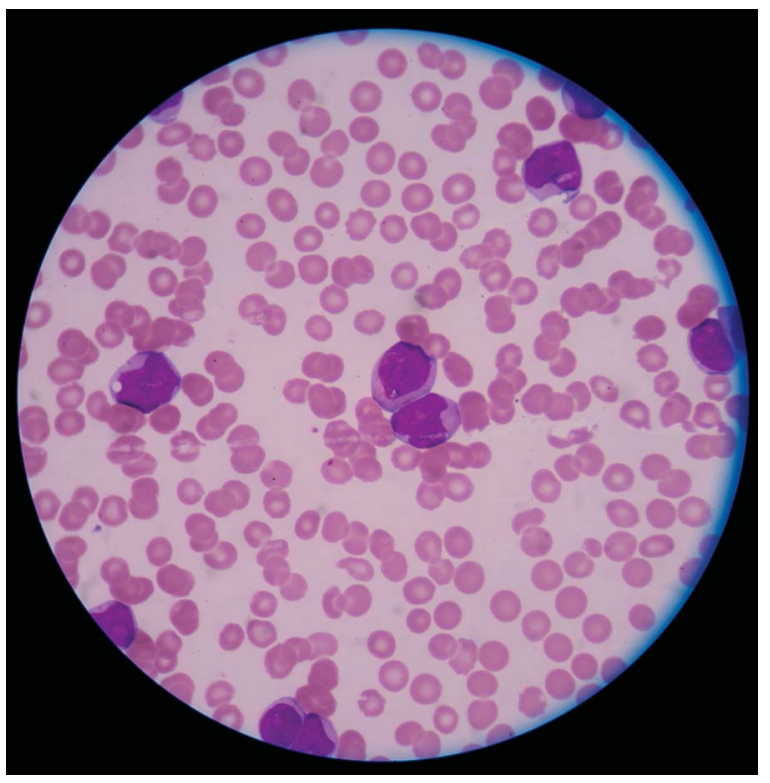
12 months, respectively; of these, $0.1 \%$ and $0 \%$, respectively, developed ALCs $<500 \mathrm{~mm}^{3}$ persisting $\geq 6$ months at any time. Evidence of ALC improvement following DMF discontinuation was observed. DMF efficacy was not substantially different in patients with and without lymphopenia. Conclusion: Lymphocyte monitoring provides effective means for early identification of patients at risk for developing severe, prolonged lymphopenia.

Neurol Clin Pract 2016;6:220-229

Mellen Center for Multiple Sclerosis Treatment and Research (RJF), Cleveland Clinic, Cleveland, OH; St. Josef Hospital (AC, RG), Ruhr University, Bochum, Germany; Multiple Sclerosis Program (JTP), Baylor Institute for Immunology Research, Dallas, TX; Medical University of Lodz (KS), Lodz, Poland; and Biogen (IC, MN, JR, JLM), Cambridge, MA. Dr. Novas is currently with Alexion Pharmaceuticals, Chesire, CT; and Dr. Rana is currently with Sanofi-Genzyme, Cambridge, MA.

Coinvestigators are listed at Neurology.org/cp.

Funding information and disclosures are provided at the end of the article. Full disclosure form information provided by the authors is available with the full text of this article at Neurology.org/cp. The Article Processing Charge was paid by the study sponsor Biogen.

This is an open access article distributed under the terms of the Creative Commons Attribution-NonCommercialNoDerivatives License 4.0 (CC BY-NC-ND), which permits downloading and sharing the work provided it is properly cited. The work cannot be changed in any way or used commercially.

Correspondence to: FOXR@ccf.org 


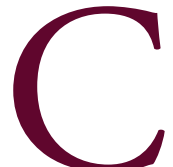

urrent management strategies for relapsing-remitting multiple sclerosis (RRMS) are focused on prevention of new disease activity via disease-modifying therapies (DMTs)., ${ }^{1,2}$ Delayed-release dimethyl fumarate (DMF; also known as gastroresistant DMF) is a DMT with potential immunomodulatory and neuroprotective effects. ${ }^{3,4}$ DMF is indicated for the treatment of patients with RRMS. ${ }^{5}$ In clinical trials, DMF was associated with flushing and gastrointestinal events as well as reduced white blood cell (WBC) and absolute lymphocyte counts (ALCs). ${ }^{6,7}$ Current US prescribing information recommends obtaining a complete blood count, including ALC, before initiating and during DMF treatment and considering treatment interruption in patients with ALCs $<500 \mathrm{~mm}^{3}$ persisting $>6$ months ${ }^{5}$ to minimize the risk of developing severe, prolonged lymphopenia and its potential complications. We conducted an integrated analysis of data from phase $2 \mathrm{~b}$ and 3 studies of DMF to characterize ALC profiles and to examine efficacy in DMF-treated patients with and without lymphopenia.

\section{METHODS}

\section{Standard protocol approvals, registrations, and patient consents}

This analysis is based on data from 1 phase $2 \mathrm{~b}$ study (NCT00168701), 2 pivotal phase 3 studies (DEFINE [NCT00420212]; CONFIRM [NCT00451451]), and an ongoing long-term extension of DEFINE/CONFIRM (ENDORSE [NCT00835770]). Each study was approved by central and local ethics committees and conducted in accordance with the International Conference on Harmonisation Guidelines for Good Clinical Practice and the Declaration of Helsinki. All patients provided written informed consent.

\section{Study design and treatment}

The study designs have been described in detail previously ${ }^{6-9}$; a brief summary is provided here.

The phase $2 \mathrm{~b}$ study and DEFINE/CONFIRM were multicenter, randomized, doubleblind, placebo-controlled, parallel-group trials of DMF monotherapy in RRMS. The 12-month phase $2 \mathrm{~b}$ study included a 6-month placebo-controlled period (part 1) and a 6 -month uncontrolled safety extension (part 2). During part 1, patients were randomized equally to DMF $120 \mathrm{mg}$ once daily, $120 \mathrm{mg}$ tid, $240 \mathrm{mg}$ tid, or placebo.

In the 2-year DEFINE/CONFIRM studies, patients were randomized equally to DMF $240 \mathrm{mg}$ bid, $240 \mathrm{mg}$ tid, or matching placebo. CONFIRM also included a glatiramer acetate (GA) reference comparator arm (not reported here).

ENDORSE is an ongoing multicenter, parallel-group, dose-blinded extension of DEFINE/ CONFIRM with up to 8 additional years of follow-up. Patients who received DMF $240 \mathrm{mg}$ bid or tid for up to 2 years in the parent studies remained on the same dosage in ENDORSE. Patients who received placebo (DEFINE and CONFIRM) or GA (CONFIRM) in the parent studies were randomized equally to DMF $240 \mathrm{mg}$ bid or tid.

\section{Patients}

Key patient inclusion criteria for all studies included age 18-55 years, RRMS diagnosis $\left(\mathrm{McD}\right.$ onald criteria $^{10}$ ), and an Expanded Disability Status Scale (EDSS) score of 0-5.0. Key exclusion criteria were relapse within 50 days before randomization, treatment with corticosteroids within 30 (phase $2 \mathrm{~b}$ study) or 50 (DEFINE and CONFIRM) days before randomization, and prior treatment with potent immunosuppressant agents/procedures or MS therapies within predefined washout periods. Exclusion criteria included prespecified abnormal laboratory parameters, including WBC count $<3,500 / \mathrm{mm}^{3}$ or eosinophils $>700 / \mathrm{mm}^{3}$.

\section{Hematology}

Blood was collected every 4 weeks in the phase $2 \mathrm{~b}$ study. In DEFINE and CONFIRM, blood was collected every 4 weeks for the first 3 months and every 12 weeks thereafter, and within 
1 month after study withdrawal or completion if a patient did not continue in the extension. Blood was collected every 12 weeks in ENDORSE.

Hematology assessments included hemoglobin, hematocrit, red blood cell count, WBC count (with differential), and platelet count. ALCs were graded according to the Common Terminology Criteria for Adverse Events (CTCAE v4.0) as follows: grade 0 ( $\geq$ lower limit of normal $\left.[\mathrm{LLN}]\left[\geq 910 \mathrm{~mm}^{3}\right]\right)$; grade $1\left(<\mathrm{LLN}\right.$ to $\left.\geq 800 \mathrm{~mm}^{3}\right)$; grade $2\left(<800-500 \mathrm{~mm}^{3}\right)$; grade $3\left(<500-200 \mathrm{~mm}^{3}\right)$; and grade $4\left(<200 \mathrm{~mm}^{3}\right) .{ }^{11}$

\section{Statistical analysis}

For the analysis of ALCs, the data from all patients exposed to DMF in DEFINE, CONFIRM, ENDORSE, and the phase $2 \mathrm{~b}$ study, including the 6-month safety extension phase, were pooled to identify all patients with low ALC values on DMF treatment. The data cutoff for this interim report was May 14, 2014; the minimum ENDORSE study follow-up for those patients remaining on study was approximately 3 years.

Because the efficacy evaluation was based on annualized relapse rate (ARR) at 2 years vs placebo, only data from DEFINE and CONFIRM were included. The ARR was analyzed in each ALC subgroup (all ALC $\geq L L N$ vs $\geq 1$ ALC $<L L N$ ) using a negative binomial regression model adjusted for baseline EDSS score, age, region, study, and number of relapses in the 12 months before study entry. Because there were no cases of ALC $<$ LLN in the placebo group, each of the DMF ALC subgroups was compared with the entire placebo group in the ARR analysis. The ALC subgroup definition used in this analysis ( $\geq$ LLN throughout and $\geq 1$ ALC $<$ LLN) allowed an adequate sample size in each subgroup for a reliable estimate of ARR reduction vs placebo.

\section{RESULTS}

\section{Patients}

The safety population comprised 2,513 patients with RRMS, including 1,136 patients treated with DMF $240 \mathrm{mg}$ bid, 1,249 treated with DMF $240 \mathrm{mg}$ tid, and 128 treated with lower doses of DMF. Mean (SD) time on study treatment was 3.1 (2.2) years (total of 7,250.0 cumulative patient-years); $74 \%, 55 \%, 29 \%$, and $1 \%$ of patients were on study treatment for $\geq 1,3,5$, and 7 years, respectively (table e- 1 at Neurology.org/cp). A total of 2,470 patients $(98.3 \%$ ) had any post-baseline ALC (median [range] follow-up: 39.0 [0.0-90.5] months).

\section{Mean WBC counts and ALCs throughout time with continuing DMF treatment}

Mean baseline ALCs were similar across the DMF treatment arms: $1,870 / \mathrm{mm}^{3}$ with lower doses of DMF, $1,980 / \mathrm{mm}^{3}$ with $240 \mathrm{mg}$ bid, and $1,990 / \mathrm{mm}^{3}$ with $240 \mathrm{mg}$ tid. Mean ALCs decreased by approximately $30 \%$ during the first year of treatment and then plateaued, remaining above LLN $\left(910 \mathrm{~mm}^{3}\right)$ throughout the observation period (figure $\left.1 \mathrm{~A}\right)$.

\section{Incidence of CTCAE grade 0-4 lymphopenia}

In most patients in the safety population $(61 \% ; 1,533 / 2,513)$, ALCs were within normal limits at all visits (CTCAE grade 0). The incidence of worst post-baseline CTCAE grade 1 and 2 lymphopenia was $9 \%(236 / 2,513)$ and $21 \%(528 / 2,513)$, respectively. A further $7 \%$ $(\mathrm{n}=171 / 2,513)$ experienced CTCAE grade 3 lymphopenia and $<1 \%(\mathrm{n}=2 / 2,513)$ experienced CTCAE grade 4 lymphopenia.

\section{ALC profiles}

Among patients treated for $\geq 6$ months ( $\mathrm{N}=2,099), 47(2.2 \%)$ experienced ALCs $<500 \mathrm{~mm}^{3}$ that persisted for $\geq 6$ months. For these patients, ALCs generally remained $<500 \mathrm{~mm}^{3}$ with continued therapy. ALCs remained $\geq \mathrm{LLN}$ in $84 \%$ of patients $(2,083 / 2,470)$ during the first 6 months and in $76 \%(1,876 / 2,470)$ during the first year; of these patients, $0.1 \%(3 / 2,083)$ and $0 \%(0 / 1,876)$, respectively, developed ALCs 


\section{Figure 1 Mean ALCs ( \pm SE) throughout time}

A

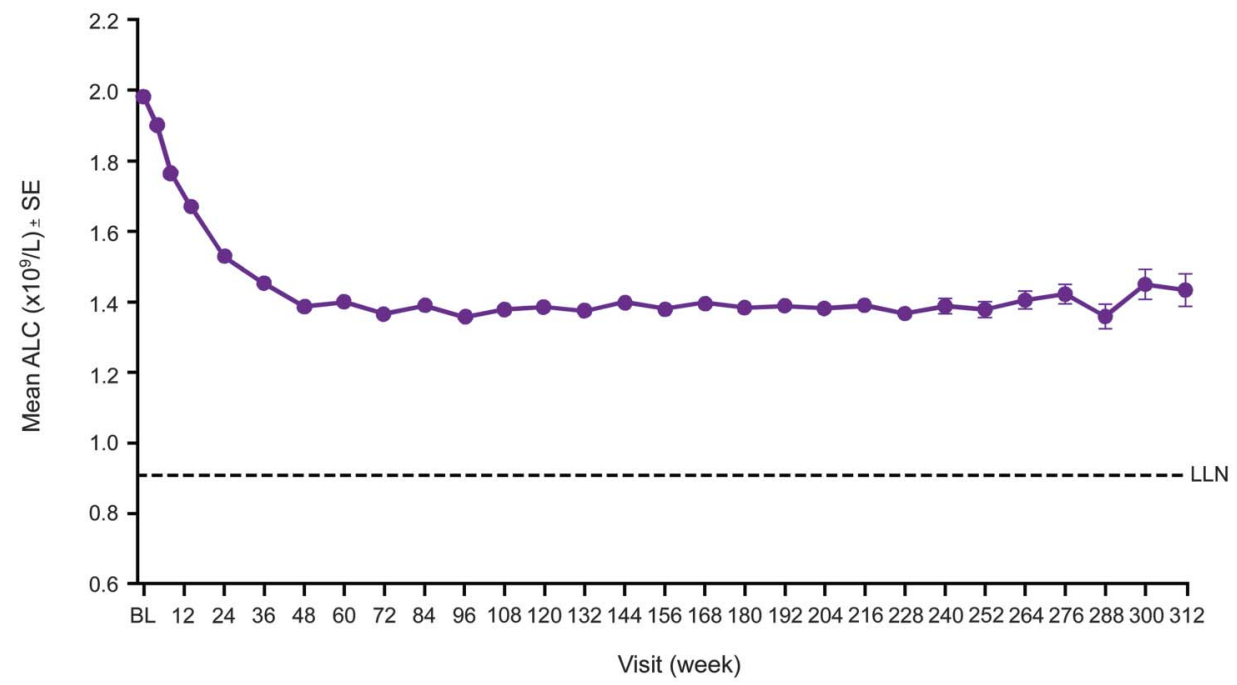

Patients with evaluable data

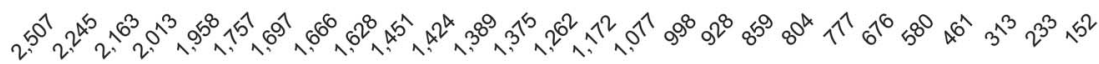

B

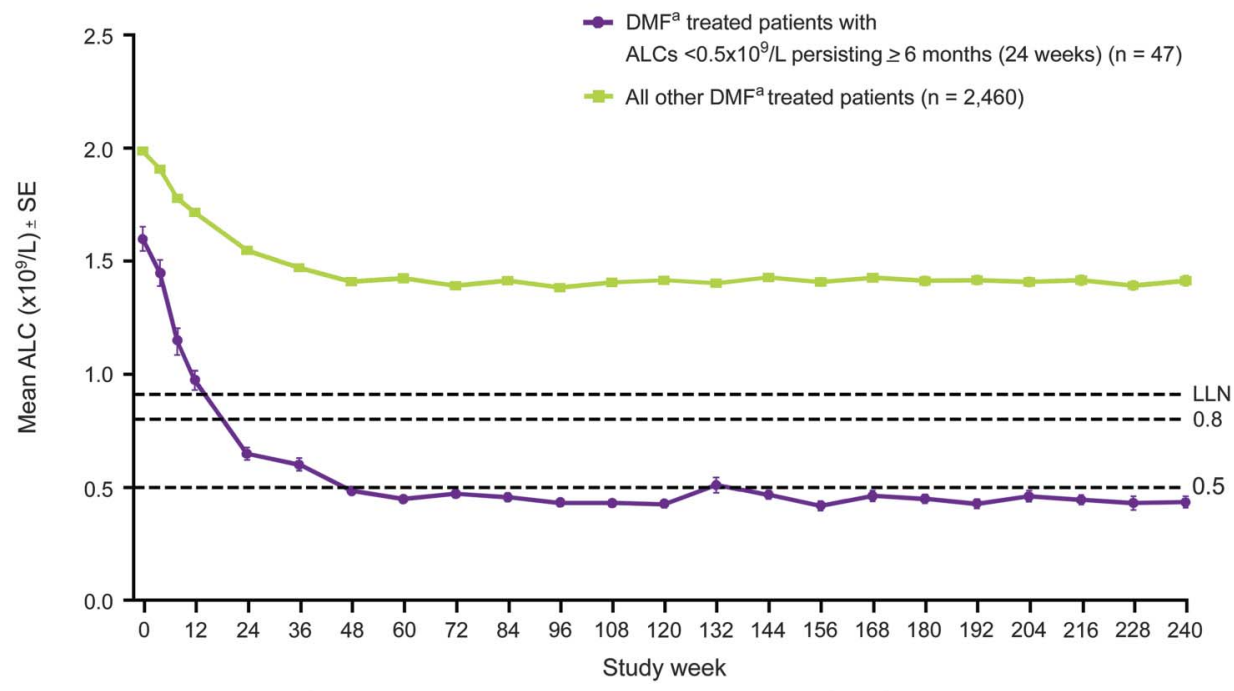

Patients with

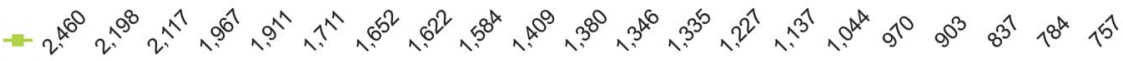
$\begin{array}{lllllllllllllllllllllllll}\text { evaluable data, } & \rightarrow & 47 & 47 & 46 & 46 & 47 & 46 & 45 & 44 & 44 & 42 & 44 & 43 & 40 & 35 & 35 & 33 & 28 & 25 & 22 & 20 & 20\end{array}$

(A) Patients treated with lower doses of DMFa, DMF $240 \mathrm{mg}$ bid, or DMF $240 \mathrm{mg}$ tid. (B) Patients with ALCs $<500 \mathrm{~mm}^{3}$ persisting $\geq 6$ months vs all other patients. ALC = absolute lymphocyte count; $\mathrm{BL}=$ baseline; $\mathrm{DMF}$ = dimethyl fumarate; LLN = lower limit of normal. aDMF, delayed-release DMF (also known as gastro-resistant DMF). 'Baseline (week 0 ) $n$ includes all patients for whom a baseline ALC value was available. cMean ALCs throughout time are presented out to approximately 5 years (week 240), as this is the minimum follow-up for patients remaining on study in ENDORSE.

$<500 \mathrm{~mm}^{3}$ persisting for $\geq 6$ months at any time (table 1 ). The percentages of patients with all ALCs $\geq 800$ or $\geq 500 \mathrm{~mm}^{3}$ during the first 6 months or during the first year of treatment who developed ALCs $<500 \mathrm{~mm}^{3}$ persisting for $\geq 6$ months at any time were similarly low $(0 \%-1.5 \%)$. However, for patients with $\geq 1$ ALC $<800 \mathrm{~mm}^{3}$ during the first 6 months or first year of treatment, the proportion who developed ALC $<500 \mathrm{~mm}^{3}$ persisting for $\geq 6$ months was higher $(15 \%$ and $11 \%$, respectively). For patients with $\geq 1$ ALC 


\begin{tabular}{|c|c|c|c|}
\hline \multirow[t]{3}{*}{ Table 1} & \multicolumn{3}{|c|}{$\begin{array}{l}\text { Proportion of patients who subsequently developed ALCs }<500 \mathrm{~mm}^{3} \text { persisting } \\
\geq 6 \text { months at any time (up to } 7 \text { years after initiating treatment) according to ALCs } \\
\text { within the first } 6 \text { months or } 1 \text { year of DMF }{ }^{2} \text { treatment }\end{array}$} \\
\hline & & \multicolumn{2}{|c|}{$\begin{array}{l}\mathrm{n} / \mathrm{N}(\%) \text { developing ALCs }<500 \mathrm{~mm}^{3} \text { persisting } \geq 6 \mathrm{mo} \\
\text { by ALCs within first } 6 \mathrm{mo} \text { or } 1 \mathrm{y}\end{array}$} \\
\hline & & First 6 mo & First 1 y \\
\hline \multicolumn{2}{|c|}{ All ALCs $\geq L_{L N}{ }^{b}$} & 3/2,083 (0.1) & 0/1,876 (0) \\
\hline \multicolumn{2}{|c|}{ All ALCs $\geq 800 \mathrm{~mm}^{3}$} & $9 / 2,219(0.4)$ & 0/2,050 (0) \\
\hline \multicolumn{2}{|c|}{ All ALCs $\geq 500 \mathrm{~mm}^{3}$} & $37 / 2,446$ (1.5) & $16 / 2,409(0.7)$ \\
\hline \multicolumn{2}{|c|}{ At least 1 ALC $<800 \mathrm{~mm}^{3}$} & 38/251 (15) & $47 / 420(11)$ \\
\hline \multicolumn{2}{|c|}{ At least $1 \mathrm{ALC}<500 \mathrm{~mm}^{3}$} & 10/24 (42) & $31 / 61$ (51) \\
\hline \multicolumn{4}{|c|}{$\begin{array}{l}\text { Abbreviations: } A L C=\text { absolute lymphocyte count; DMF = dimethyl fumarate; } L L N=\text { lower limit of } \\
\text { normal. }\end{array}$} \\
\hline
\end{tabular}

$<500 \mathrm{~mm}^{3}$ during the first 6 months or first year of treatment, the percentage of patients who developed ALCs $<500 \mathrm{~mm}^{3}$ persisting for $\geq 6$ months at any time was considerably higher ( $42 \%$ and $51 \%$, respectively) (table 1$)$.

\section{Time course of mean ALC changes in patients with ALCs $<500 \mathrm{~mm}^{3}$ persisting $\geq 6$ months}

Mean ALCs in patients with ALCs $<500 \mathrm{~mm}^{3}$ persisting for $\geq 6$ months showed a faster decline than those in counterparts without ALCs $<500 \mathrm{~mm}^{3}$ persisting for $\geq 6$ months (figure 1B), decreasing to $650 \mathrm{~mm}^{3}$ by week 24 and to $480 \mathrm{~mm}^{3}$ by week 48 .

\section{Recovery of ALCs post discontinuation of DMF treatment}

Among the 47 patients with ALCs $<500 \mathrm{~mm}^{3}$ for $\geq 6$ months, 9 discontinued or completed the study and had limited posttreatment data, as shown in figure 2. Of these 9 patients, 8 had ALCs $\geq 1$ month after their final dose. All of these patients generally showed ALC increases following their final DMF dose. The remaining 38 patients with ALCs $<500 \mathrm{~mm}^{3}$ for $\geq 6$ months remained on treatment at the time of this analysis (May $14,2014)$.

\section{Efficacy in patients with and without lymphopenia (<LLN)}

In DEFINE and CONFIRM, the reduction in ARR at 2 years in patients treated with DMF $240 \mathrm{mg}$ bid vs placebo was not substantially different in patients with lymphopenia ( $\geq 1$ ALC $<$ LLN) compared to those without lymphopenia (all ALCs $\geq$ LLN) (rate ratio [95\% confidence interval] vs placebo: $0.472[0.364-0.611]$ and 0.547 [0.441-0.679], respectively), figure 3 .

\section{General safety}

As identified in this interim analysis, lymphopenia in DMF-treated patients was not associated with an overall increased risk of serious infections, including opportunistic infections. The incidence of serious infection was low $(83 / 2,513 ; 3 \%)$. Also, there was no apparent relationship between increased incidence of serious infection and increased lymphopenia grade. Serious infections were reported in 3\% $(\mathrm{n}=43), 6 \%(\mathrm{n}=13)$, and $4 \%(\mathrm{n}=22)$ of patients with CTCAE grade 0,1 , or 2 lymphopenia, respectively, and in $3 \%(\mathrm{n}=5)$ with CTCAE grade 3 or 4 lymphopenia. The most common infections were abdominal and gastrointestinal $(\mathrm{n}=20)$, urinary tract $(\mathrm{n}=14)$, and upper respiratory tract $(\mathrm{n}=10)$, and all occurred with an incidence of $<1 \%$ in the patient population overall. Subsequent to the 
Figure 2 ALCs following treatment discontinuation in 9 patients with ALCs $<500 \mathrm{~mm}^{3}$ for at least 6 months

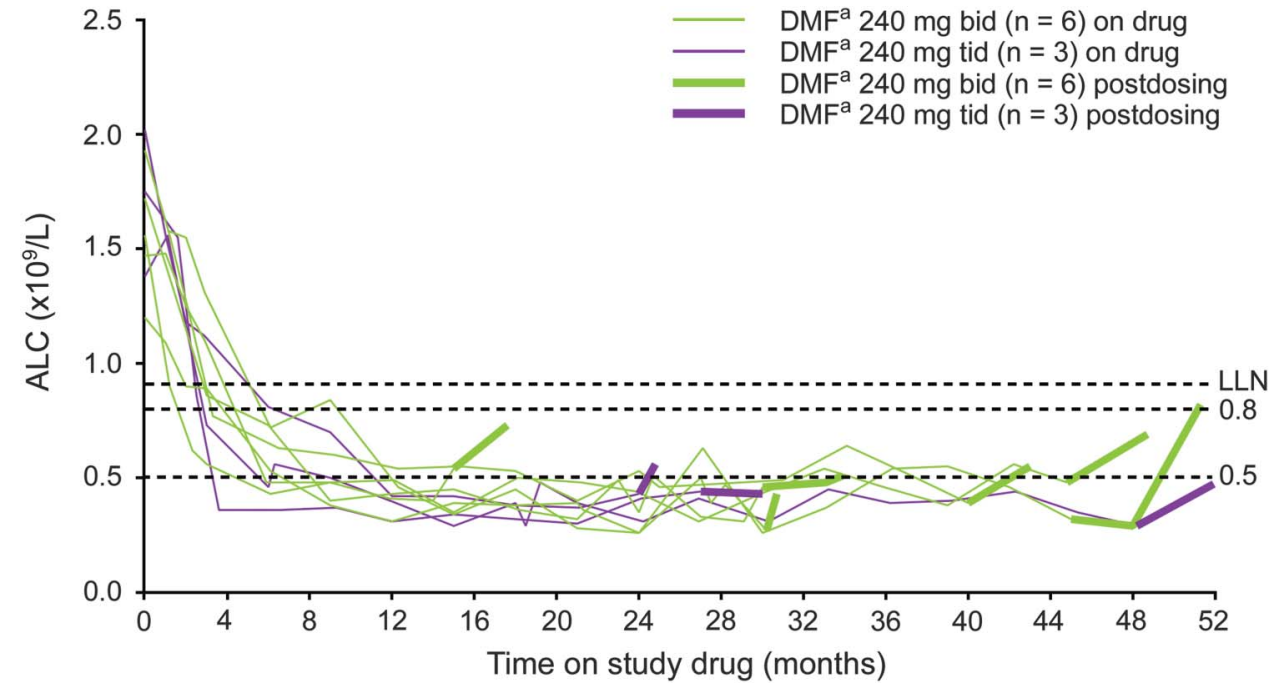

ALC = absolute lymphocyte count; DMF = dimethyl fumarate; LLN = lower limit of normal. aDMF, delayed-release DMF (also known as gastro-resistant DMF).

data cutoff for this interim report, a case of progressive multifocal leukoencephalopathy (PML) in a patient treated with DMF $240 \mathrm{mg}$ tid was reported in the setting of severe, prolonged lymphopenia (approximately $<500 \mathrm{~mm}^{3}$ for 3.5 years). Details of this case are reported separately. ${ }^{12}$

\section{Figure 3 ARR reduction at 2 years in patients with and without lymphopenia in DEFINE and} CONFIRM

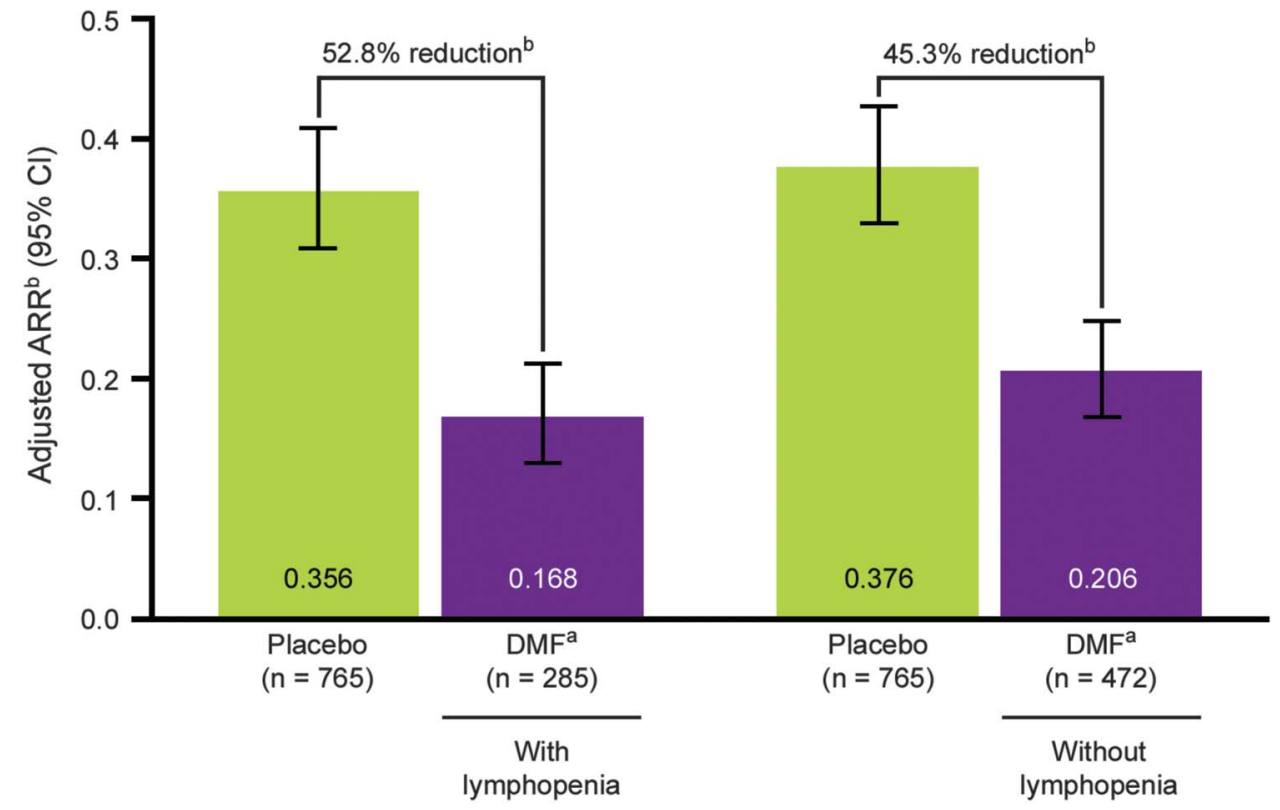

Results represent ARR reductions in patients in the DMF bid group with lymphopenia (at least 1 ALC $<$ LLN) or without lymphopenia (all ALCs $\geq$ LLN) compared with all patients in the placebo group (pooled analysis of DEFINE and CONFIRM). ALC = absolute lymphocyte count; $\mathrm{ARR}=$ annualized relapse rate; $\mathrm{Cl}$ = confidence interval; $\mathrm{DMF}=$ dimethyl fumarate; EDSS = Expanded Disability Status Scale; LLN = lower limit of normal. aDMF, delayed-release DMF (also known as gastro-resistant DMF). 'Based on negative binomial regression, adjusted for baseline EDSS score ( $\leq 2.0$ vs $>2.0$ ), baseline age ( $<40$ vs $\geq 40$ years), region, and number of relapses in the 1 year before study entry. 


\section{Lymphocyte monitoring provides an effective} means for early identification of patients at risk for subsequently developing severe, prolonged lymphopenia.

\section{DISCUSSION}

A key objective of this analysis was to provide practical considerations for the management of DMF-treated patients with MS by characterizing ALC profiles and examining efficacy in patients with and without lymphopenia. ALC profiles were generally stable throughout time. Mean ALCs decreased by approximately 30\% in DMF-treated patients during the first year of treatment and then plateaued, remaining above the LLN throughout the observation period. Among patients treated with DMF for $\geq 6$ months, few (2.2\%) experienced ALCs $<500 \mathrm{~mm}^{3}$ persisting for $\geq 6$ months, and subsequent ALCs of these patients generally remained $<500 \mathrm{~mm}^{3}$. This suggests that ALC $<500 \mathrm{~mm}^{3}$ persisting for $\geq 6$ months was an early predictor for those patients at risk of developing severe, prolonged lymphopenia. Our results indicate that patients with ALCs $\geq$ LLN for the first 6 months and first year on DMF treatment are unlikely to have ALC $<500 \mathrm{~mm}^{3}$ persisting for $\geq 6$ months. Thus, lymphocyte monitoring provides an effective means for early identification of patients at risk for subsequently developing severe, prolonged lymphopenia.

Recent labeling changes in the United States include a recommendation to consider interruption of DMF in patients with ALCs $<500 \mathrm{~mm}^{3}$ persisting $>6$ months to minimize the risk of subsequently developing severe, prolonged lymphopenia and its potential complications. ${ }^{5}$ Similar labeling changes are pending in the European Union. Although data are limited and based on a small number of patients $(n=9)$, the current interim data provide preliminary evidence for ALC improvement following DMF discontinuation in patients with an ALC $<500 \mathrm{~mm}^{3}$ persisting for $\geq 6$ months. To further study the recovery profile in patients with decreases in lymphocyte counts who are considered at risk for severe and prolonged lymphopenia, a recent ENDORSE protocol amendment stipulated that study treatment must be temporarily withheld if a patient's ALC is $<500 \mathrm{~mm}^{3}$ for $>6$ months. If the ALC remains $<500 \mathrm{~mm}^{3}$ for 24 weeks after the last dose, study treatment must be permanently discontinued. It is anticipated that this protocol amendment will enable further evaluation of lymphocyte count recovery after temporary withholding or permanent discontinuation of DMF in patients who develop ALCs $<500 \mathrm{~mm}^{3}$ persisting for $>6$ months.

As of August 31, 2015, more than 170,000 patients have been treated with DMF worldwide, representing more than 170,000 patient-years of exposure. Of these patients, 3,887 received DMF in clinical trials, which equates to 8,640 patient-years of exposure (clinical trial exposure data as of April 15, 2015). In this analysis, the overall incidence of serious infections was low, and there was no apparent correlation between the incidence of infection and CTCAE grade ALC (patients with CTCAE grade 3 or 4 ALC did not experience a higher incidence of serious infection than patients with CTCAE grade 0 or 1 ALC). Subsequent to the data cutoff for this interim report (May 2014), a fatal case of PML was reported in a 54-year-old patient with MS treated with delayed-release DMF $240 \mathrm{mg}$ tid in the setting of severe, prolonged lymphopenia (approximately $<500 \mathrm{~mm}^{3}$ for 3.5 years). ${ }^{12}$ In addition, rare cases of PML occurred in the postmarketing setting in the presence of prolonged lymphopenia. Specifically, 2 cases occurred in the presence of severe and prolonged lymphopenia (approximately $<500 \mathrm{~mm}^{3}$ persisting for $>6$ months) and 1 case occurred in the presence of moderate and prolonged lymphopenia (nadir $600 \mathrm{~mm}^{3}$ for $>6$ months) (Biogen data on file). Aside from rare cases of PML, there is no overall increased risk for serious infections, including other opportunistic 


\section{As of August 31, 2015, more than 170,000 patients have been treated with DMF worldwide, representing more than 170,000 patient-years of exposure.}

infections. ${ }^{13}$ Rare cases of PML have also been reported with other fumarates ${ }^{14-16}$; however, it is important to note that Fumaderm is a distinct product with different active ingredients and that compounded fumarates are unregulated products that may contain different active ingredients. These products have different pharmacokinetic and pharmacodynamic profiles and may have a differential effect on lymphocytes (Biogen data on file $)^{17}$; however, one salient feature of these cases is prolonged lymphopenia, as the majority of these cases shared this characteristic. Periodic monitoring of ALCs to identify patients who may have developed severe, prolonged lymphopenia is therefore recommended (as per the label for DMF). Furthermore, health care providers should assess the benefit and risk of continued DMF treatment in patients who experience moderate lymphopenia persisting for $>6$ months.

Immune cell changes are an important component in MS pathophysiology, as the immune system plays a central role in myelin and nervous cell destruction and lesion development. ${ }^{18,19}$ The beneficial effects of immunomodulatory and immunosuppressive therapies on MS disease activity provide further support to this theory. Herein, we noted similar DMF therapeutic efficacy (ARR reduction) in patients with and without lymphopenia, suggesting that lymphopenia is not a primary mechanism for the therapeutic effects of DMF.

Our findings are supported by independent research findings in the real-world setting. In a retrospective chart review evaluating effects of DMF on lymphocytes in patients with MS ( $\mathrm{n}=221$ ) prescribed DMF over a 2-year period, grade 3 lymphopenia was reported in approximately $5 \%$ of patients. ${ }^{20}$ DMF-induced lymphopenia also did not predict clinical response in that study. A second retrospective chart review $(n=159)$ reported an incidence of DMF-associated lymphopenia (all grades) of $45 \%$ ( $41 \%$ grade $1 / 2,4 \%$ grade 3 ), consistent with that observed in clinical trials; the mean ALC nadir $\left(1,220 \mathrm{~mm}^{3}\right)$ was within normal limits and occurred at a mean of 10.5 months. ${ }^{21}$

The underlying mechanism of DMF-induced lymphopenia is not well understood. DMFdependent lymphocyte reduction has not been observed in any preclinical species, including chronic primate studies, indicating that this phenomenon is specific to human biology. This restriction to humans is a major hindrance to identification and characterization of the underlying molecular mechanisms of lymphopenia. Preliminary findings suggest that DMF affects several lymphocyte populations, most notably $\mathrm{CD} 4^{+}$and $\mathrm{CD} 8^{+}$cells, potentially eliciting a greater reduction in the latter. ${ }^{22,23}$ However, despite these preliminary findings, the role of lymphocyte subsets in the action of DMF is unknown. Further research is ongoing to determine the link between DMF and lymphopenia, including its effect on lymphocyte subsets and the mechanisms responsible for these effects.

The results of this integrated analysis suggest the overall benefit-risk of DMF remains favorable. ALC profiles in DMF-treated patients with RRMS were generally stable throughout time. ALC $<500 \mathrm{~mm}^{3}$ persisting for $\geq 6$ months appeared to be an early predictor for the development of severe, prolonged lymphopenia in a small number of DMF-treated patients; however, there was no evidence suggesting an association between the rate of serious infections and incidence of lymphopenia. Comparable therapeutic efficacy in patients with and without lymphopenia suggests that lymphopenia is not a primary mechanism of action of DMF. 


\section{REFERENCES}

1. Goodin DS, Frohman EM, Garmany GP Jr, et al. Disease modifying therapies in multiple sclerosis: report of the Therapeutics and Technology Assessment Subcommittee of the American Academy of Neurology and the MS Council for Clinical Practice Guidelines. Neurology 2002; 58:169-178

2. Rio J, Comabella M, Montalban X. Multiple sclerosis: current treatment algorithms. Curr Opin Neurol 2011;24:230-237.

3. Albrecht P, Bouchachia I, Goebels N, et al. Effects of dimethyl fumarate on neuroprotection and immunomodulation. J Neuroinflammation 2012;9:163.

4. Linker RA, Lee DH, Ryan S, et al. Fumaric acid esters exert neuroprotective effects in neuroinflammation via activation of the Nrf2 antioxidant pathway. Brain 2011;134:678-692.

5. Tecfidera [package insert]. Cambridge, MA: Biogen, Inc; 2014.

6. Fox RJ, Miller DH, Phillips JT, et al. Placebo-controlled phase 3 study of oral BG-12 or glatiramer in multiple sclerosis. N Engl J Med 2012;367:1087-1097.

7. Gold R, Kappos L, Arnold DL, et al. Placebo-controlled phase 3 study of oral BG-12 for relapsing multiple sclerosis. N Engl J Med 2012;367:1098-1107.

8. Kappos L, Gold R, Miller DH, et al. Efficacy and safety of oral fumarate in patients with relapsingremitting multiple sclerosis: a multicentre, randomised, double-blind, placebo-controlled phase IIb study. Lancet 2008;372:1463-1472.

9. Pozzilli C, Phillips JT, Fox RJ, et al. Long-term follow-up of the safety of delayed-release dimethyl fumarate in RRMS: interim results from the ENDORSE extension study. Neurology 2015;84:P7. 235.

10. Polman CH, Reingold SC, Edan G, et al. Diagnostic criteria for multiple sclerosis: 2005 revisions to the "McDonald Criteria". Ann Neurol 2005;58:840-846.

11. National Cancer Institute. Common Terminology Criteria for Adverse Events v4.0, NCI, NIH, DHHS. Bethesda, MD: NIH publication; 2009. \#09-7473.

12. Rosenkranz T, Novas M, Terborg C. PML in a patient with lymphocytopenia treated with dimethyl fumarate. N Engl J Med 2015;372:1476-1478.

13. Van Schependom J, Gielen J, Laton J, Nagels G. Assessing PML risk under immunotherapy: if all you have is a hammer, everything looks like a nail. Mult Scler 2016;22:389-392.

14. van Oosten BW, Killestein J, Barkhof F, et al. PML in a patient treated with dimethyl fumarate from a compounding pharmacy. N Engl J Med 2013;368:1658-1659.

15. Ermis U, Weis J, Schulz JB. PML in a patient treated with fumaric acid. N Engl J Med 2013;368: 1657-1658.

16. Nieuwkamp DJ, Murk J-L, van Oosten BW, et al. PML in a patient without severe lymphocytopenia receiving dimethyl fumarate. N Engl J Med 2015;372:1474-1476.

17. Hoepner R, Faissner S, Salmen A, et al. Influence of ethyl hydrogen fumarate vs. dimethylfumarate on the development of lymphopenia. Mult Scler J 2015;368(S11):584-585.

18. Hemmer B, Nessler S, Zhou D, Kieseier B, Hartung HP. Immunopathogenesis and immunotherapy of multiple sclerosis. Nat Clin Pract Neurol 2006;2:201-211.

19. Wu GF, Alvarez E. The immunopathophysiology of multiple sclerosis. Neurol Clin 2011;29: 257-278.

20. Longbrake EE, Cross AH. Dimethyl fumarate associated lymphopenia in clinical practice. Neurology 2015;84:P3.240.

21. Robb JF, Hyland M, Samkoff L. Dimethyl fumarate associated lymphopenia in clinical practice: implications for informed patient management. Presented at the Consortium of Multiple Sclerosis Centers (CMSC) Annual Meeting; May 27-30, 2015; Indianapolis, IN.

22. Khatri BO, Garland J, Berger J, et al. The effect of dimethyl fumarate (Tecfidera) on lymphocyte counts: a potential contributor to progressive multifocal leukoencephalopathy risk. Mult Scler Relat Disord 2015;4:377-379.

23. Longbrake EE, Ramsbottom MJ, Piccio L, Cross AH. Dimethyl fumarate effects on lymphocyte phenotype. Presented at the Consortium of Multiple Sclerosis Centers (CMSC) Annual Meeting; May 27-30, 2015; Indianapolis, IN.

Received August 28, 2015. Accepted in final form November 30, 2015.

\section{AUTHOR CONTRIBUTIONS}

Dr. Fox served on the medical advisory committee of the parent study, contributed to the conception and design of the study, participated as an investigator and collected data, interpreted the data, and revised the manuscript. Dr. Chan participated as an investigator and collected data, interpreted the data, and revised 
the manuscript. Dr. Gold served on the medical advisory committee of the parent study, contributed to the conception and design of the study, participated as an investigator and collected data, interpreted the data, and revised the manuscript. Dr. Phillips served on the medical advisory committee of the parent study, contributed to the conception and design of the study, participated as an investigator and collected data, interpreted the data, and revised the manuscript. Dr. Selmaj served on the medical advisory committee of the parent study, contributed to the conception and design of the study, participated as an investigator and collected data, interpreted the data, and revised the manuscript. Dr. Chang analyzed and interpreted the data and revised the manuscript. Dr. Novas contributed to the conception and design of the study, interpreted the data, and revised the manuscript. Dr. Rana interpreted the data and revised the manuscript. Dr. Marantz provided medical oversight of the study, interpreted the data, and revised the manuscript.

\section{ACKNOWLEDGMENT}

Ray Zhang, PhD, of Biogen provided assistance with statistical analyses. Biogen provided funding for medical writing support in the development of this paper; Julie Adkins and Erin Bekes, PhD, from Complete Medical Communications provided editorial support. Biogen reviewed and provided feedback on the paper to the authors. The authors had full editorial control of the paper, and provided their final approval of all content.

\section{STUDY FUNDING}

Supported by Biogen.

\section{DISCLOSURES}

R.J. Fox serves on scientific advisory boards for Biogen and Novartis; serves on the editorial boards of Neurology and Multiple Sclerosis Journal; receives publishing royalties for Multiple Sclerosis and Related Disorders (Demos Medical, 2013); serves as a consultant for Actelion, Biogen, GlaxoSmithKline, Questcor, MedDay, Novartis, Mallinckrodt, Teva, and XenoPort; and receives research support from Novartis, National MS Society, NIH, and Consortium of MS Centers. A. Chan served on scientific advisory boards for Bayer, Biogen, Genzyme, Novartis, and UCB; has received honoraria from Bayer, Biogen, Genzyme, Merck, Novartis, Teva Neuroscience, Almirall Hermal GmbH, Sanofi Aventis, and Roche; is author on a patent re: Proteomic profile of NMO; serves as a consultant for Bayer Schering, Biogen, Genzyme, Merck, Novartis, and UCB; receives research support from Bayer Schering, Biogen, Merck Serono, Novartis, Genzyme, German Ministry for Education and Research (BMBF), and Ruhr University Bochum; has participated in medico-legal cases; and served as country lead investigator for phase III DEFINE trial on dimethyl fumarate in multiple sclerosis and as country lead investigator for phase III TEMSO and TENERE trials (teriflunomide in MS). R. Gold serves on three DSMB boards for TEVA and on scientific advisory boards for Biogen, Bayer Schering, and Novartis; has received honoraria from Biogen, TEVA, Bayer Schering, Merck Serono, and Novartis; receives compensation from Sage for serving as editor of Therapeutic Advances in Neurological Disorders and on the editorial boards of American Journal of Pathology, Journal of Neuroimmunology, and Experimental Neurology; serves as a consultant for Biogen, ELAN, TEVA, and Chugai Inc.; and receives research support from TEVA, Biogen, Bayer Schering, Merck Serono, and Novartis. J.T. Phillips has served on a scientific advisory board for Serono and received speaker honoraria from Acorda, Biogen, Genzyme, and Sanofi; serves on speakers' bureaus for Acorda, Biogen, Genzyme, and Sanofi; and receives research support from Biogen and Roche. K. Selmaj serves on scientific advisory boards for Genzyme, Biogen, Novartis, Synthon, Roche, Receptos, and TEVA; has received speaker honoraria from Biogen, Novartis, TEVA, Bayer, Roche, Receptos, and Genzyme; serves on the editorial board of Journal of Neuroimmunology; serves as a consultant for Genzyme, Novartis, Ono, Teva, Biogen, Roche, Synthon, and Merck Serono; serves on speakers' bureaus for Novartis, Merck Serono, Biogen, Bayer, and Genzyme; and receives research support from National Research Center (Poland) and from National Center for Research and Development. I. Chang is an employee of and holds stock/stock options in Biogen. J. L. Marantz is an employee of and holds stock/stock options in Biogen. Full disclosure form information provided by the authors is available with the full text of this article at Neurology.org/cp. 


\title{
Neurology ${ }^{\circ}$ Clinical Practice
}

\section{Characterizing absolute lymphocyte count profiles in dimethyl fumarate-treated patients with MS: Patient management considerations \\ Robert J. Fox, Andrew Chan, Ralf Gold, et al.}

\author{
Neurol Clin Pract 2016;6;220-229 Published Online before print April 1, 2016 \\ DOI 10.1212/CPJ.0000000000000238
}

This information is current as of April 1, 2016

\begin{tabular}{|c|c|}
\hline $\begin{array}{l}\text { Updated Information \& } \\
\text { Services }\end{array}$ & $\begin{array}{l}\text { including high resolution figures, can be found at: } \\
\text { http://cp.neurology.org/content/6/3/220.full.html }\end{array}$ \\
\hline Supplementary Material & $\begin{array}{l}\text { Supplementary material can be found at: } \\
\text { http://cp.neurology.org/content/supp1/2016/04/03/CPJ.0000000000000 } \\
\text { 238.DC1 } \\
\text { http://cp.neurology.org/content/supp1/2016/04/03/CPJ.0000000000000 } \\
\text { 238.DC2 }\end{array}$ \\
\hline References & $\begin{array}{l}\text { This article cites } 19 \text { articles, } 0 \text { of which you can access for free at: } \\
\text { http://cp.neurology.org/content/6/3/220.full.html\#\#ref-list-1 }\end{array}$ \\
\hline Citations & $\begin{array}{l}\text { This article has been cited by } 13 \text { HighWire-hosted articles: } \\
\text { http://cp.neurology.org/content/6/3/220.full.html\#\#otherarticles }\end{array}$ \\
\hline Subspecialty Collections & $\begin{array}{l}\text { This article, along with others on similar topics, appears in the } \\
\text { following collection(s): } \\
\text { Multiple sclerosis } \\
\text { http://cp.neurology.org//cgi/collection/multiple_sclerosis }\end{array}$ \\
\hline Permissions \& Licensing & $\begin{array}{l}\text { Information about reproducing this article in parts (figures,tables) or in } \\
\text { its entirety can be found online at: } \\
\text { http://cp.neurology.org/misc/about.xhtml\#permissions }\end{array}$ \\
\hline Reprints & $\begin{array}{l}\text { Information about ordering reprints can be found online: } \\
\text { http://cp.neurology.org/misc/addir.xhtml\#reprintsus }\end{array}$ \\
\hline
\end{tabular}

Neurol Clin Pract is an official journal of the American Academy of Neurology. Published continuously since 2011, it is now a bimonthly with 6 issues per year. Copyright $\odot 2016$ American Academy of Neurology. All rights reserved. Print ISSN: 2163-0402. Online ISSN: 2163-0933.

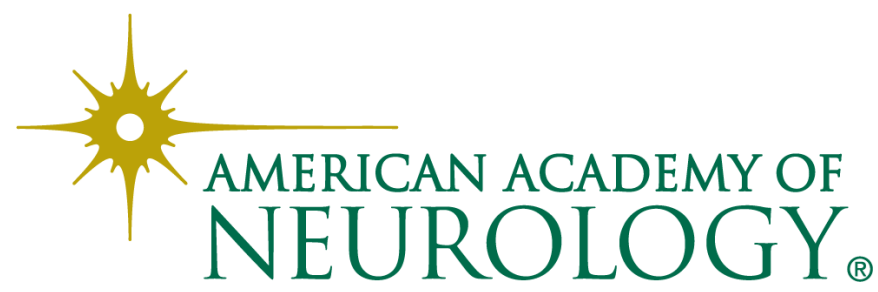

